Ann. Zootech., I978, 27 (2), 267-288.

\title{
Utilisation de la mélasse de canne à sucre dans l'alimentation du porc : essai d'interprétation des acquisitions récentes
}

\author{
R. CHRISTON et J. IAE DIVIDICH
}

Station de Recherches sur l'Élevage des Porcs, Centre national de Recherches Zootechniques, I.N.R.A., $7835^{\circ}$ Jouy-en-Josas (France)

\section{Résumé}

Cette revue est consacrée aux connaissances acquises au cours des 20 dernières années sur la composition chimique et l'utilisation expérimentale de la mélasse finale de canne à sucre par le Pore.

Pour une teneur en eau de is à $25 \mathrm{p}$. cent, la mélasse renferme une importante fraction glucidique : son extractif non-azoté représente environ $65 \mathrm{p}$. cent du produit frais, constitués en majeure partie de glucides solubles dans l'eau ou dans l'alcool $(58,7 \mathrm{p}$. cent), essentiellement le saccharose $(34,6$ p. cent), le glucose $(8,5 \mathrm{p}$. cent) et le fructose $(9,9 \mathrm{p}$. cent); environ $7 \mathrm{p}$. cent de la fraction glucidique sont de nature inconnue. Par contre, elle est pauvre en azote $(0,56 \mathrm{p}$. cent environ) et présente, en outre, une teneur élevée en matières minérales ( $8 \mathrm{p}$. cent en moyenne). Ainsi, il s'agit d'un aliment énergétique par l'importance de ses constituants glucidiques, bien que sa teneur en énergie brute soit relativement faible $\left(285^{\circ} \mathrm{Kcal} / \mathrm{kg}\right.$ de produit brut et $3800 \mathrm{Kcal} / \mathrm{kg}$ de matière sèche).

L'introduction de mélasse à des taux importants dans le régime (ro à 40 p. cent en poids) a des répercussions sur les performances zootechniques et sur le fonctionnement du tube digestif des monogastriques. Chez le porcelet aussi bien que chez le porc de 20 à roo $\mathrm{kg}$, on observe une baisse des performances de croissance et d'efficacité alimentaire. Cet effet peut toutefois être limité, chez le porc en croissance-finition, en augmentant la concentration énergétique de la ration mélassée par addition d'un aliment riche en énergie. Par ailleurs, l'ingestion de fortes proportions de mélasse entraîne une diminution du rendement d'abattage, liée en particulier à l'élévation du poids du tractus digestif et, en revanche, à une réduction de l'adiposité des carcasses.

La baisse des performances zootechniques enregistrée s'explique, tant chez le jeune que chez le porc plus âgé, par la faible valeur en énergie digestible de la mélasse (2 4 oo Kcal F.D. $/ \mathrm{kg}$ ) et par son effet dépressif sur la rétention azotée, dû principalement à une excrétion accrue d'azote métabolique fécal. En outre, l'introduction de taux croissants de mélasse dans la ration des porcs (surtout des porcelets) provoque l'apparition d'un état diarrhéique quelquefois mortel. On peut difficilement admettre la seule responsabilité de la forte teneur en cendres (et particulièrement en potassium) de la mélasse, ou bien celle de sa seule déficience en élément encombrant pour expliquer ces désordres digestifs. Ceux-ci sont vraisemblablement le résultat d'une digestion et/ou d'une absorption incomplètes des glucides de la mélasse, créant, dans le caecun et le gros intestin, un milieu à $1 \mathrm{a}$ fois hypertonique et favorable aux fermentations. L'augmentation de l'activité 
spécifique de l'invertase intestinale, observée chez le Rat en présence de mélasse dans la ration, tendrait à montrer, comme cela a été rapporté chez le porcelet, l'intérêt d'une adaptation préalable des animaux à cet aliment pour en améliorer l'utilisation.

Enfin, sur le plan zootechnique, les taux optimum d'incorporation de mélasse de canne dans le régime peuvent varier de $20 \mathrm{p}$. cent pour le porcelet à $3^{\circ} \mathrm{p}$. cent pour le Porc en croissancefinition et la Truie en gestation.

\section{Introduction}

La canne à sucre, principale culture des pays en voie de développement, représente, avec une production annuelle de $693 \times 10^{6}$ tonnes (FAO, I976), une importante ressource alimentaire. Le traitement de la plante fournit en effet 70 millions de tonnes de sucre et plusieurs sous-produits, parmi lesquels la mélasse finale (environ $\mathrm{r} 8 \times \mathrm{I0}^{6} \mathrm{t}$ ) est le plus intéressant. Le terme "mélasse finale ", plus généralement appelé "mélasse ", désigne les résidus du jus de canne obtenus après sa clarification et l'extraction du sucre.

Une partie de la mélasse est transformée, par fermentation et distillation, en alcool; une autre sert de substrat pour la culture de levures. Son utilisation extensive dans l'alimentation animale et notamment dans celle du porc, en substitution des céréales dont la culture est parfois impossible en raison des conditions climatiques, pourrait constituer un élément favorable au développement de la production porcine dans les pays tropicaux. De nombreux travaux relatifs à 1'utilisation de la mélasse dans l'alimentation des animaux sont disponibles, ainsi qu'en témoignent les revues de Scott (I953), Ferrando et Theodossiades (Ig60) et de MONETTI (I967). Cependant, bien des inconnues subsistent encore, concernant sa composition chimique, les facteurs limitants d'origine digestive et métabolique les causes et les conséquences des troubles diarrhéiques qu'elle entraîne chez le Porc.

L'objet de la présente revue est de résumer l'état actuel de nos connaissances sur la valeur alimentaire de la mélasse dans la ration du Porc, à partir des études réalisées au cours de ces vingt dernières années.

\section{1. - Composition chimique de la mélasse de canne à sucre}

Les principaux résultats obtenus par l'analyse de la mélasse sont présentés dans le tableau $\mathrm{I}$.

\section{I.I. - Caractéristiques physicochimiques}

La mélasse est une substance brunâtre, visqueuse, dont la teneur en eau varie habituellement entre I5 et $25 \mathrm{p}$. cent. Sa densité s'élève à I, 35 environ et son $\mathrm{pH}$ est légèrement acide. Selon quelques auteurs, notamment Spencer et MEAdE (I957), cités par OBANDO et al. (I969), elle contient 5 à 6 p. cent d'acides organiques, dont la moitié sous forme combinée à l'état de sels ou d'esters. L'acide aconitique 


\section{TABLEAU I}

Composition chimique et énergie brute de la mélasse finale de canne à sucre (exprimées par rapport au produit frais), selon différents auteurs ( ${ }^{*}$ )

Chemical composition and gross energy content of sugar cane final molasses (on air dry basis), according to several authors $\left({ }^{*}\right)$

a)

Composition (p. cent)

(Percentage composition)

\begin{tabular}{|c|c|}
\hline $\begin{array}{l}\text { Moyenne } \\
(\text { Mean })\end{array}$ & $\begin{array}{l}\text { Valeurs extrêmes } \\
\text { (Extreme values) }\end{array}$ \\
\hline 76,8 & $7 \mathrm{r}, \mathrm{O}-80,0$ \\
\hline 8,4 & $5,5-$ I 1,3 \\
\hline $0, \mathrm{I}$ & $0,0-0,3$ \\
\hline 64,6 & $51,7-69,0$ \\
\hline $5^{8}, 7$ & $50,0-69,7$ \\
\hline 34,6 & $29,6-37,8$ \\
\hline 16,2 & $13,9-17,0$ \\
\hline 8,6 & $5,5-\mathrm{I} 4,0$ \\
\hline 9,9 & $I, 3-I 6,0$ \\
\hline 3,6 & $1,5-10,2$ \\
\hline $379 I$ & 36 IO -4 II 4 \\
\hline
\end{tabular}

Matière sèche (Dry matter).

Cendres $(A s h)$

Matières grasses $(F a t)$.

Extractif non azoté (Nitrogen free extract). . . . . . . . . .

Glucides solubles (Soluble carbohydrates). . . . . . . . . . .

Saccharose (Sucrose). . . . . . . . . . . . . . . . . . .

Glucides réducteurs (Reducing sugars). . . . . . . . . . . .

Glucose (Glucose) . . . . . . . . . . . . . . . . . . . . .

Fructose (Frnctose) . . . . . . . . . . . . . . . . . . .

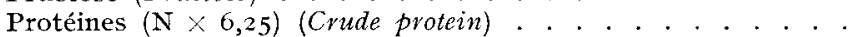

Énergie brute (Kcal $/ \mathrm{kg}$ de matière sèche) (Gross energy (kcal/kg

dry mattev). . . . . . . . . . . . . . . . . . . . . . .

Composition minérale

(Inorganic compounds)

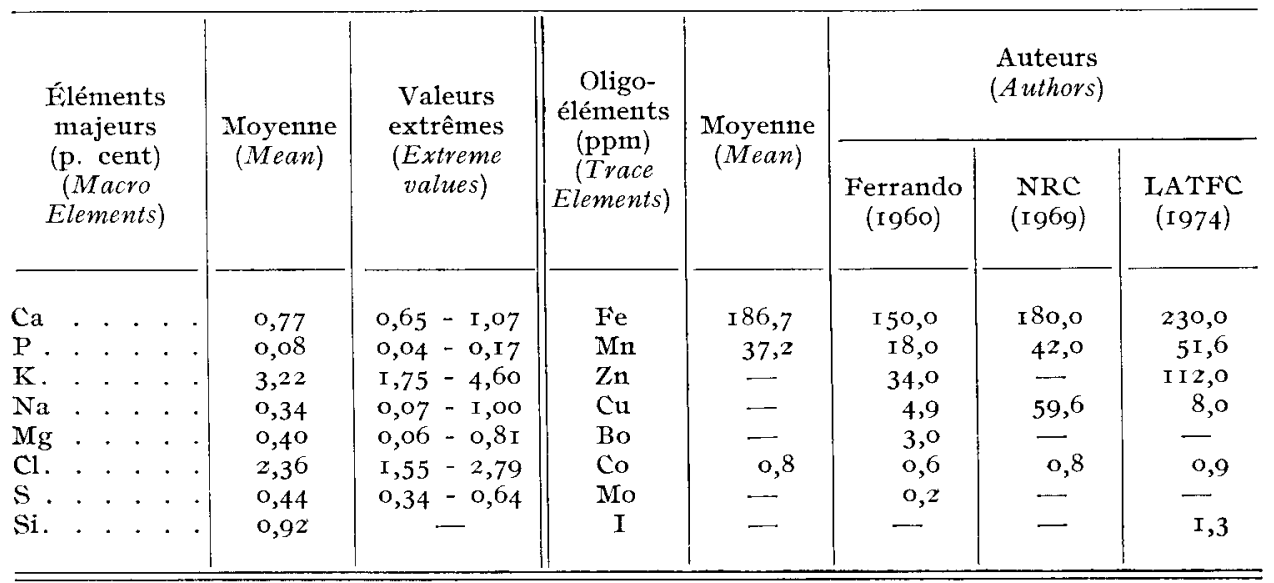


TABLEAU I (suite)

c)

Vitamines

(Vitamins)

\begin{tabular}{|c|c|c|c|c|c|}
\hline \multirow{2}{*}{$\begin{array}{l}\text { Vitamines (ppm) } \\
\text { Vitamins }(p p m)\end{array}$} & \multirow{2}{*}{$\begin{array}{l}\text { Moyenne } \\
\text { (Mean) }\end{array}$} & \multicolumn{4}{|c|}{ Auteurs (Authors) } \\
\hline & & $\begin{array}{c}\text { Binkley } \\
\text { Wolfrom } \\
\text { (I953) }\end{array}$ & $\begin{array}{l}\text { Ferrando } \\
\text { (I960) }\end{array}$ & $\begin{array}{l}\text { NRC } \\
\text { (1969) }\end{array}$ & $\begin{array}{l}\text { LATFC } \\
\text { (1974) }\end{array}$ \\
\hline Thiamine (Thiamine) . & 0,87 & 0,7 & 0,9 & 0,9 & $\mathrm{I}, \mathrm{O}$ \\
\hline Riboflavine (Riboflavin) $\cdot \cdot \cdot \cdot \cdot \cdot \cdot$ & 2,72 & 2,0 & 2,6 & 3,3 & 3,0 \\
\hline Acide pantothénique (Pantothenic acid) & $4 \mathrm{I}, 6 \mathrm{O}$ & $5^{\circ}, 8$ & 37,8 & $3^{8,3}$ & 39,5 \\
\hline Pyridoxine (Pyridoxin). . . . . . & - & $\mathrm{I}, 5$ & - & - & 6,7 \\
\hline Niacine $($ Niacin) . . . . . . . . & $3 r, 90$ & $\mathbf{1} 7,7$ & 40,8 & 34,3 & 34,8 \\
\hline Biotine (Biotin) . . . . & - & $\mathrm{I}, 4$ & - & - & 0,7 \\
\hline Acide folique (Folic acid) & - & 0,0 & - & - & $\mathrm{O}, \mathrm{I}$ \\
\hline Choline (Choline) . . . . . . . . . & 835,50 & - & 787,5 & 876,0 & 843,0 \\
\hline
\end{tabular}

(*) Henke (1933), Binklfy et Wolfrom (I953), Morrisson (I954), Spencer et Meade (I957) in Obando et al. (I969), Ferrando et Theodossrades (I960), Fincham (I966), Macleod et al. (I968), N.R.C. (1969), Devendra et GohI. (1970), AGuIlera et al. (I97I), HANSEN, Sunesen et Bresson (I974), I,E DIVIDICH et al. (1974).

est quantitativement 1e plus important (5 à $6 \mathrm{p}$. cent dans certaines mélasses). De plus, on y trouverait, en faible quantité, des acides minéraux tel que l'acide nitrique $\left(0, \mathbf{I}_{5} \mathrm{p}\right.$. cent). Sa couleur sombre est due à l'action de la chaleur sur les protéines, en présence de glucides réducteurs.

\section{I.2. - La fraction glucidique}

Les glucides représentent environ $65 \mathrm{p}$. cent des constituants de la mélasse (tab1. ra). Ce sont essentiellement des glucides solubles : saccharose (5o à $55 \mathrm{p}$. cent des glucides totaux), fructose (I 5 p. cent) et glucose (I3 p. cent). D'autres glucides, quoi qu'en plus faible proportion, ont été identifiés : le xylose, 1'arabinose, des gommes et des pectines (HENkE, I933; SPENCER et MEADE, I957, cités par Obando et al., I969). La présence de mannitol, laxatif couramment utilisé en thérapeutique humaine est également signalée dans la mélasse de canne (BINKLEY et WoLFrom, I953). Enfin, une partie de cette fraction glucidique ( 7 p. cent environ) reste indéterminée. Elle pourrait représenter des déhydroglucides résultant de l'action des hautes températures, associée à un $\mathrm{pH}$ très alcalin, sur les glucides solubles connus de la mélasse (BInkLEy et Wolfrom, I953). Comme le proposent ces auteurs, les modifications susceptibles d'affecter les molécules de glucose et de fructose peuvent entraîner, d'une part la transformation de glucose en fructose, d'autre part la production de composés furfuriques dont la présence a été récemment con firmée dans la mélasse de canne par Yokota et FAGERSON (I97I). 


\section{I.3. - La fraction azotée}

D'une façon générale, la teneur en azote total de la mélasse est faible et se situe entre 0,4 et I,7 p. cent (tabl. I a). Elle varie cependant avec les conditions culturales appliquées à la canne et notamment avec l'importance de la fumure azotée et la richesse du sol en matières organiques (MORRISON, I954; Combs et WALIACE, I970; AGUILERA et al., I97I).

A part les faibles quantités constituant les " substances colorantes ", l'azote de la mélasse se trouverait principalement sous forme d'acides aminés libres et de bases azotées (BINKLFY et WOLFROM, I953). Nos résultats (tab1. 2) confirment la

\section{TABI EAU 2}

Répartition des matières azotées de la mélasse

Composition en acides aminés, compavée à celles de l'auf et du mä̈s (LE DrvidICH et al., I977) Distribution of crude protein in molasses

A mino acid composition as compared with that of egg and maize (LE DIVIDICI et al., I977)

\begin{tabular}{|c|c|c|c|}
\hline $\begin{array}{l}\text { Matières azotées } \\
\text { (Crude protein) }\end{array}$ & $\begin{array}{l}\text { Mélasse } \\
\text { (Molasses) }\end{array}$ & $\begin{array}{l}\text { œuf entier } \\
\text { (Whole egg) }\end{array}$ & $\begin{array}{c}\text { Maïs } \\
\text { (Maize) }\end{array}$ \\
\hline$N$ total (p. cent) Total $N(p$. cent $) \ldots$ & 0,58 & -- & - \\
\hline$N-$ Acides aminés (p. cent) $N-A$ mino acids ( $p$. cent) . & 0,22 & - & 一 \\
\hline $\begin{array}{l}\text { Amino acids }(\mathrm{g} / 16 \mathrm{gN})\left({ }^{(1)}\left(\text { Amino acids }(\mathrm{g} / 16 \mathrm{gN})\left({ }^{(}\right)\right)\right. \\
\text {Lysine }(\text { Lysine })\end{array}$ & 0,6 & $7 \mathrm{~T}$ & 2,9 \\
\hline Histidine (Histidine) . . . . . . . . . . . . . & 0,3 & 2,6 & 2,7 \\
\hline 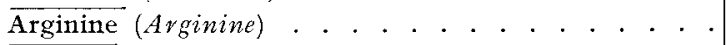 & 0,5 & 6,4 & 4,4 \\
\hline$\overline{\text { Acide aspartique }(\text { Aspartic acid) } . . . . . . . . ~}$ & 22,4 & 9,9 & 6,1 \\
\hline Thréonine (Threonine) . . . . . . . . . . & 1,5 & 4,8 & 3,4 \\
\hline Sérine $($ Serine). . . . . . . . . . . . . & 2,0 & $7, \mathrm{x}$ & 4,6 \\
\hline Acide glutamique (Glutamic acid) . . . . . . & 10,6 & 12,7 & 17,7 \\
\hline Proline (Proline). . . . . . . . . & $\mathrm{I}, 3$ & 4,0 & 10,0 \\
\hline Glycine (Glycine $) \ldots \ldots$ & 1,6 & 3,2 & 3,5 \\
\hline Alanine (Alanine) . . . . . . . . . & 4,6 & 5,6 & 7,2 \\
\hline Valine $($ Valine $) \ldots \ldots$ & 2,3 & 7,0 & 5,0 \\
\hline 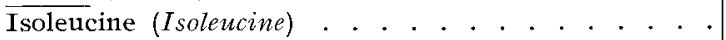 & $\mathbf{I}, \mathbf{I}$ & 5,5 & 3,8 \\
\hline 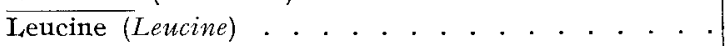 & $\mathrm{I}, 3$ & 8,5 & I $\mathrm{I}, 8$ \\
\hline Tyrosine $($ Tyrosine $) \ldots \ldots \ldots$ & 0,7 & 3,8 & 4,0 \\
\hline Phénylalanine (Phenylalanine). . . . . . . & 0,8 & 4,8 & 4,4 \\
\hline 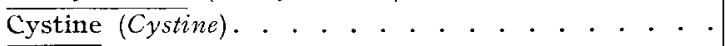 & 0,6 & 2,8 & 2,4 \\
\hline Méthionine (Methronine) . . . . . . . & 0,5 & 3,3 & 2,0 \\
\hline 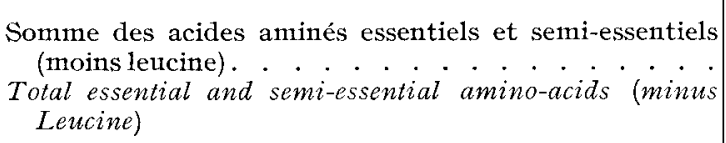 & IO,2 & $4^{8}, \mathrm{r}$ & 35,0 \\
\hline
\end{tabular}

(1) Les acides aminés essentiels sont soulignés (Essential amino-acids are underlined.) 
faible teneur en azote total de la mélasse et montrent que moins de la moitié ( $3^{8} \mathrm{p}$. cent) provient des acides $\alpha$-aminés. Ainsi, la conversion de l'azote total en protéines à l'aide du coefficient 6,25 s'avère tout à fait erronée dans le cas de la mélasse.

\section{I.4. - Teneur en énergie brute}

L'énergie brute de la mélasse s'élève à environ $3800 \mathrm{Kcal} / \mathrm{kg}$ de matière sèche (N.R.C., I969; L.A.T.F.C., I974; LE Drvidich et al., I974). Elle est donc faible comparativement à celle des autres aliments du bétail et notamment à celle des céréales. Cela s'explique en grande partie par l'importance de sa fraction minérale et par la teneur en énergie brute du saccharose, du fructose et du glucose plus faible que celle de l'amidon (tabl. 3).

\section{TABLEAU 3}

Énergie brute de la mélasse comparée à celle de quelques aliments du bétail et à celle de ses principaux constituants glucidiques (Kcal/kg de MS)

Gross energy content of molasses as compared with that of some common feedstuffs and that of its carbohydrate constituents (Kcal/kg DM)

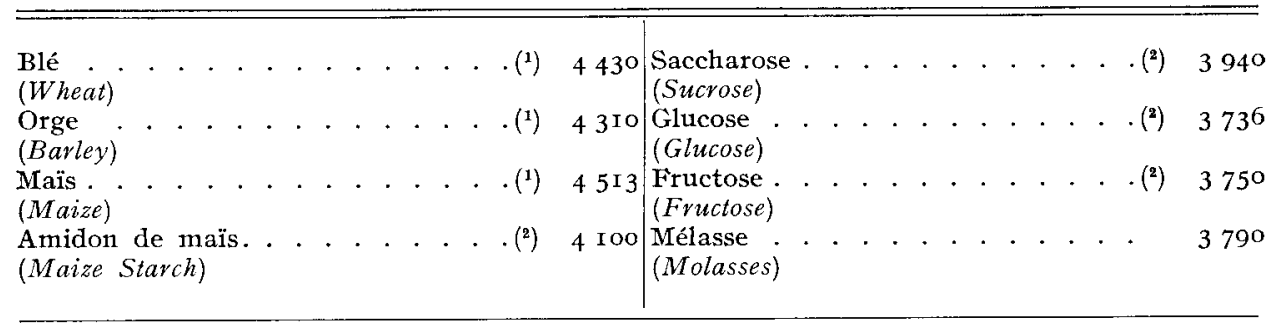

(1) Selon (According to) HeNRy (I968).

( $\left.{ }^{2}\right)$ D'après (According to) the "Handbook of Chemistry and Physics ", 45" éd., 1964-I965.

\section{I.5. - Les minéraux}

La mélasse se caractérise par une grande richesse en matières minérales ( 8 p. cent du poids frais en moyenne). Plus précisémient, elle est très riche en potassium qui représente environ $40 \mathrm{p}$. cent de la totalité des éléments minéraux (tabl. I $b$ ) Elle est, par ailleurs, relativement bien pourvue en calcium $(8 \mathrm{~g} / \mathrm{kg})$, probablement en raison de 1'introduction de chaux lors de la défécation du jus de canne, au cours de la fabrication du sucre. En revanche, la mélasse est pauvre en phosphore total (moins de I $\mathrm{g} / \mathrm{kg}$ par rapport à 3,0 et 4,0 dans le maïs et l'orge respectivement); il en résulte un rapport $\frac{\mathrm{Ca}}{\mathrm{P}}$ voisin de ıo, donc très déséquilibré, alors qu'il varie entre $0, \mathrm{I}$ et 0,2 pour la plupart des aliments végétaux.

Les oligo-éléments sont assez bien représentés dans la mélasse (tabl. I $b$ ) et notamment le fer $(0,3 \mathrm{~g} / \mathrm{kg})$. On y trouve également une quantité notable de magnésium (3 à $4 \mathrm{~g} / \mathrm{kg}$ ). L,es teneurs en zinc (Io $\mathrm{mg} / \mathrm{kg}$ ), en manganèse ( $40 \mathrm{mg} / \mathrm{kg}$ ) et en cuivre $(20 \mathrm{mg} / \mathrm{kg}$ ) sont, par contre, faibles. Enfin, le cobalt, l'iode et le molybdène n'y sont présents qu'à l'état de traces. 


\section{I.6. - Les vitamines}

La mélasse est pauvre en vitamines et, notamment, dépourvue de vitamines liposolubles. Toutefois, elle renferme des quantités non négligeables de vitamines hydrosolubles, principalement du groupe B (tabl. Ic). Parmi celles-ci, les plus importantes sont : la niacine, l'acide pantothénique et la riboflavine. Mais la thiamine est totalement absente. Cette dernière qui existe dans le jus de canne est en effet très sensible à 1'action de la chaleur et est probablement détruite au cours du processus de cristallisation du sucre (BIN KLEY et WOL,FROM, I953). La mélasse contient, en outre, une forte proportion de choline.

Ainsi, d'une façon générale, la mélasse contient assez peu de vitamines nécessaires au porcelet ou au porc et, dans la formulation des aliments complets, on pourra négliger les quantités qu'elle apporte.

En conclusion, la mélasse apparaît comme une substance très pauvre en azote protéique et déséquilibrée dans sa composition minérale; elle doit, par conséquent, être considérée comme un constituant strictement énergétique des rations. En outre, il n'est pas exclu que certains des composés inconnus, qui ont pu être concentrés ou formés au cours de la fabrication du sucre, se comportent comme des produits toxiques. Ainsi, en est-il peut-être des déhydroglucides, dont les propriétés nutritionnelles sont inconnues. On a également identifié, d'abord dans le jus de canne (STEVENS, I957), puis dans la mélasse finale de canne, des composés phénoliques plus ou moins polymérisés et assimilés à des tanins, au nombre desquels figurent la dicoumarine (anticoagulant) (HASHIzUME, YAMAGAMI et SASAKI, I967).

Enfin, l'étude analytique de la mélasse montre que son utilisation dans les aliments du Porc présente des difficultés liées à la présence de composés non alimentaires et à ses nombreux déséquilibres nutritionnels.

\section{2. - Utilisation de la mélasse de canne à sucre dans l'alimentation du porc}

\section{I. - Digestibilité et digestion de la mélasse}

\section{I . Digestibilité de la mélasse et des rations à base de mélasse}

I a teneur en énergie digestible de la mélasse varie, selon les auteurs, de 3 ooo à $3500 \mathrm{Kcal}$ par $\mathrm{kg}$ de matière sèche (N.R.C., I969; LE DIVIDICH et al., I974; L.A.T.F.C., I974, MARRERo et Ly, I977). Comparée à celle des céréales, cette valeur est faible puisqu'elle ne représente que go p. cent environ de la valeur de l'orge et 80 p. cent de celle du maïs.

Chez le porcelet comme chez le porc de 20 à roo $\mathrm{kg}$, la mélasse provoque une baisse de la digestibilité apparente des principaux éléments de la ration, notamment de l'azote et de l'énergie (fig. I), d'autant plus accentuée que son taux d'incorporation au régime est plus élevé (BRooks et IWANAGA, I967; CoMBs et WALLACE, I973; LE Drvidich et al., I974; IE DIVIDICH et CANOPE, I975). La diminution particulièrement nette de 1'utilisation digestive des matières azotées a été expliquée chez le Rat (Christon et LE Dividich, I977) par une augmentation de la quantité d'azote métabolique fécal. Les conséquences sur le plan nutritionnel sont impor- 


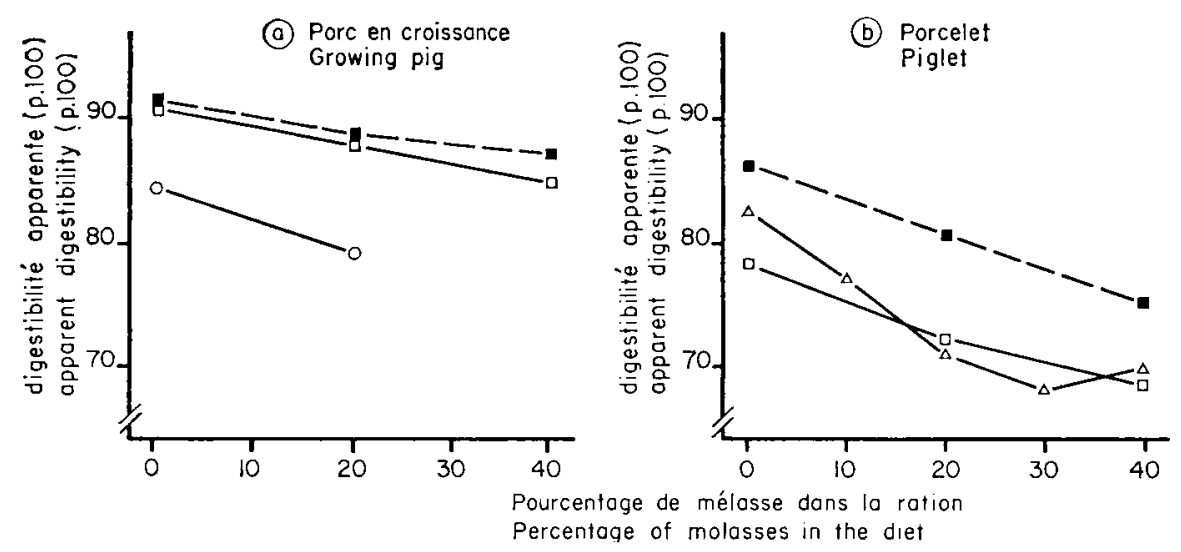

FIG. I. - Influence du taux de mélasse dans la vation sur l'utilisation digestive apparente de l'azote (-) et de l'énergie (- - ) selon divers auteurs (BRooks, I967 (0); CombS et WALIACE, 1970 ( $\triangle$ ); LE Dividich et al., 1974 ()); Le DIvidich et CANOPE, I975 (-)).

Effect of level of molasses on the apparent digestibility of nitrogen (- - ) and energy (- -) according to Brooks, I967 (O); COMBS and WALLACE, I970 (ه); LE DIVIDICH et al., I974 ()) LE DIVIDICH and CANOPE, I975 ( $)$.

tantes puisqu'à taux comparable de protéines, le régime mélassé entraîne une diminution de la rétention journalière d'azote par rapport aux animaux recevant un régime témoin, à la fois chez le Porc (LE DIVIDIch et CANOPE, I975) et chez le Rat (CHRISTON et LE DIVIDICH, I977). Il s'ensuit qu'à teneur optimale en mélasse de la ration, les performances maximum de croissance ne peuvent être obtenues qu'au prix d'une élévation du taux de protéines (tabl. 4).

Par ailleurs, la diminution de l'utilisation digestive de l'énergie de la ration consécutive à la faible digestibilité de celle de la mélasse peut provenir d'une digestion incomplète de ses glucides ou d'une réduction de leur absorption intestinale.

\section{2.r2. Digestion des glucides de la mélasse}

Le saccharose est d'abord hydrolysé en glucose et fructose, essentiellement dans la première moitié de 1'intestin grêle (MANnERs et STEVENS, I972; STEVENS et KIDDER, I972). L,es oses libérés, ainsi que le glucose et le fructose libres contenus dans la mélasse, sont absorbés par la muqueuse intestinale. Le transport du glucose se fait par voie active et plus rapidement que celui du fructose (CoRI, I925, chez l'homme; Ly, I97I, Aumaitre et al., i975, chez le Porc).

Les problèmes posés par l'utilisation de la mélasse se situent peut-être au niveau de la digestion et de l'absorption de sa fraction glucidique indéterminée. Cependant, l'observation de quantités importantes de fructose et de saccharose dans le cæcum et le gros intestin de porcs nourris à la mélasse (Ly, I97I) suggère également une déficience dans l'utilisation intestinale de ces glucides. On sait en effet que l'activité hydrolytique des disaccharidases intestinales est très sensible au contenu glucidique du régime (DEREN, BroItman et $Z_{\text {AMCHECk, I967; Grand }}$ et JAKSINA, I973; TUOVINEN et BENDER, I975) et qu'elle varie avec la nature de ces glucides (Blair, Yakimets et Tuba, ig63; Reddy, Pleasants et Wostmanr, ig68; Rosensweig et Herman, I968; Jones, Sosa et Skromak, I972). Ainsi, 


\section{TABLEAU 4}

Influence de l'augmentation du taux de protéines dans les régimes riches en mélasse sur les performances du porcelet sevré à 5 semaines

(LE Drvidich et CANOPE, données non publiées, 1974)

Influence of increasing the protein level of high molasses diets on performances of piglets weaned at 5 weeks ( $\mathrm{LE}$ DIVIDICH and CANOPE, unpublished data, I974)

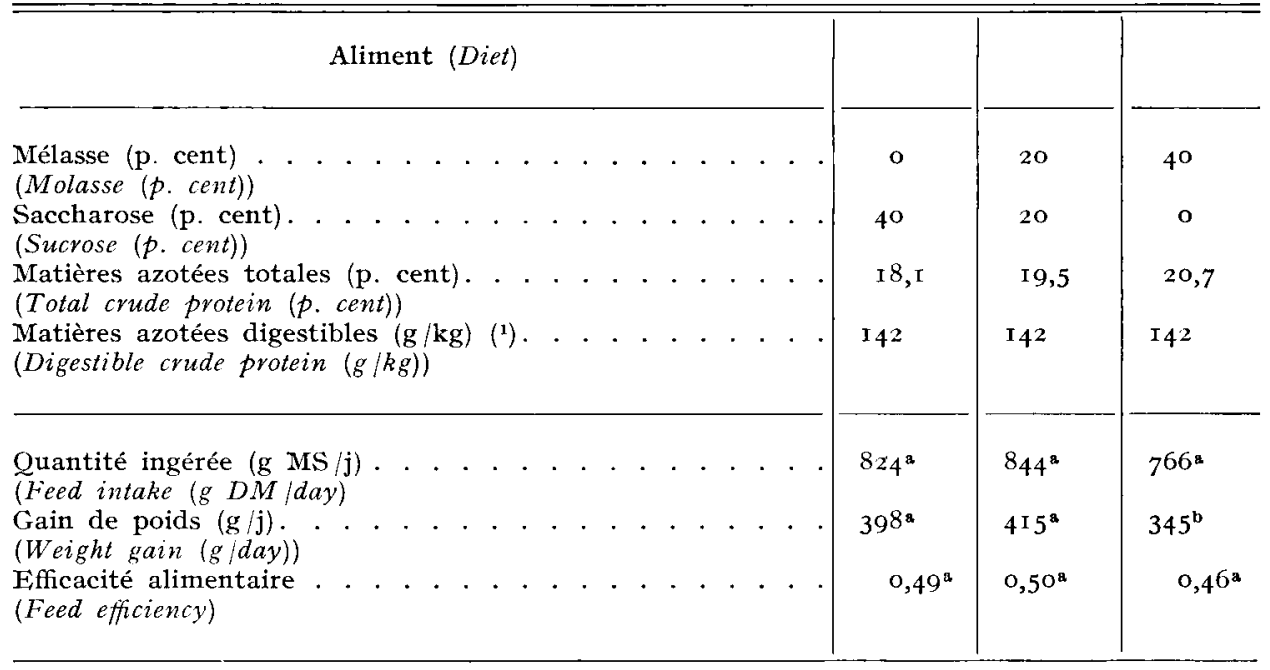

(1) Calculées selon (According to) LE Dividich et al. (1974).

Ly (I97I) observe une diminution de l'activité spécifique de l'invertase chez des porcs recevant une ration à base de mélasse " high-test " (qui est, en réalité, un sirop de canne partiellement inverti) par rapport à ceux qui reçoivent une ration à base de maïs. Nos travaux sur le rat montrent, au contraire, une augmentation importante de l'activité (totale et spécifique) de l'invertase en présence de mélasse finale de canne à sucre, comparée au saccharose (LE DIvidich et al., I977). Ces résultats conduisent à recommander une adaptation progressive du porc et surtout du porcelet à une alimentation riche en mélasse, afin de favoriser la tolérance digestive des animaux.

Ainsi, en l'état actuel des connaissances, il est impossible d'affirmer que la baisse du coefficient d'utilisation digestive de l'énergie des rations à base de mélasse est provoquée par une déficience en activité invertasique de la muqueuse intestinale. Reste alors 1'hypothèse de la digestion impossible ou incomplète de la fraction glucidique indéterminée de la mélasse et d'une saturation des enzymes digestives. Enfin, une absorption lente et incomplète du fructose et un passage de cet ose dans le gros intestin pourraient également contribuer à une réduction de la digestibilité de l'énergie de la mélasse.

\section{3. - Effet sur la croissance et l'efficacité alimentaire}

I1 convient de considérer le stade physiologique de l'animal recevant une ration à fort taux de mélasse : d'une façon générale, le porcelet présente une moins bonne tolérance à la mélasse que les animaux plus âgés (porc en croissance-finition ou truie). 


\section{3r. Chez le porcelet}

a) Utilisation en tant que facteur d'appétence:

L'importance de l'aliment complémentaire sur la croissance du porcelet allaité est bien connue (AUMAITRE, et SALMON-I,EGAGNEUR, I96I) et il importe de le faire ingérer précocément et quantitativement au jeune animal, afin de lui assurer une croissance maximum. De nombreux travaux ont souligné l'effet stimulant du saccharose sur la consommation d'aliments (LEwIs et al., I955; SAlMON-LEGAGNEUR et FÉvRIER, I956). Par contre, la mélasse, incorporée au même taux que celui du saccharose dans la ration, ne semble pas lui conférer le même avantage. Selon Notzorp et al., I955, on ne trouve aucun effet stimulant de la mélasse sur la consommation d'aliments, ce qui s'explique par le fait que la mélasse ne contient qu'environ $30 \mathrm{p}$. cent de saccharose. En raison donc de l'extrê. me sensibilité des jeunes aux désordres digestifs, la mélasse n'est pratiquement pas employée dans la formulation des aliments du premier âge.

\section{b) Utilisation en tant qu'aliment de base:}

Les recommandations concernant l'introduction de mélasse dans la ration de sevrage du porcelet sont en général prudentes; le taux d'incorporation dans 1'aliment ne dépasse pas Io p. cent (MoneTTI, I 967). Deux études récentes réalisées par ComBs et WALLACE (I973) et LE DIVIdich et al. (I974), ont cependant montré que le porcelet, sevré au poids de 5 à Io kg et non adapté préalablement à la mélasse pouvait tolérer, dans son aliment de sevrage, au moins $20 \mathrm{p}$. cent de mélasse de canne. Au delà de cette proportion, les animaux présentent un état diarrhéique

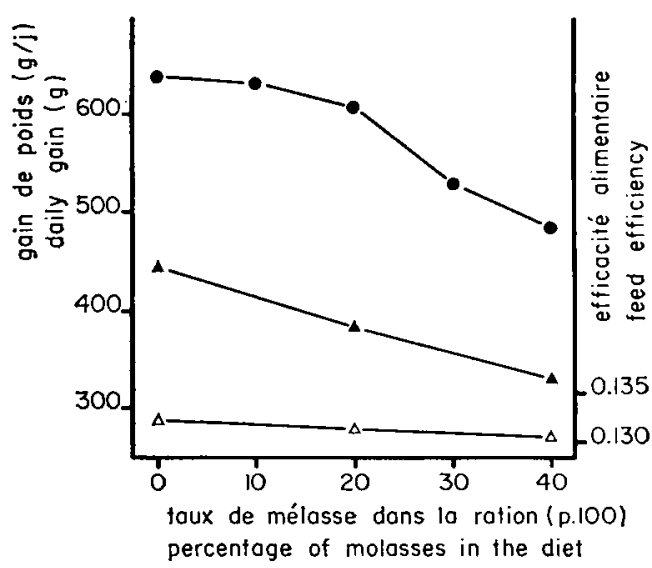

FIG. 2. - Influence du taux de mélasse dans la ration de sevrage du porcelet (de 9 à $25 \mathrm{hg}$ ) sur le gain de poids journalier $(\bullet, \Delta)$ et l'efficacité alimentaive $\Delta$ (d'après ComBs et WALrACE, I973 (•) et LE DIVIDICH et al., I974 (,$\Delta)$ ).

Effect of level of molasses in the diet of weaned piglet (from 9 to $25 \mathrm{~kg}$ ) on daily gain $(\bullet, \Delta)$ and feed efficiency $(\Delta)$ (according to COMBS and WAI, ACE, I973 $(\bullet$ ) and LE DIVIDICH et al., $1974(\Lambda, \Delta))$. 
parfois fatal (tabl. 5). Néanmoins, le taux de mélasse dans la ration peut être augmenté, sans effets défavorables sur l'état sanitaire, jusqu'à 40 p. cent, dans le cas d'une adaptation précoce du porcelet à un aliment complémentaire au lait renfermant déjà de la mélasse ( $\mathrm{L}_{\mathrm{E}}$ DIvidich, données non publiées). Sur le plan des performances de croissance, l'introduction de taux croissants de mélasse dans la ration du porcelet entraîne une diminution de la vitesse de croissance qui est due principalement à une baisse des quantités de matière sèche et d'énergie digestible ingérées. En effet, l'efficacité de l'énergie digestible pour la croissance demeure constante jusqu'à $40 \mathrm{p}$. cent de mélasse dans la ration.

\section{TABLEAU 5}

Infiuence de la teneur en mélasse de la ration sur l'état sanitaire et la mortalité des porcelets sevrés

(LE DIVIDICH et al., I974)

Influence of molasses content of the diet on health and mortality of weaned piglets

(LE DIVIDICH et al., 1974)

Taux de mélasse (p. cent).

(Molasses level ( $p$. cent))
Teneur en eau des fèces ( $p$. cent) :

(Water content of faeces ( $p$. cent)) :

$I^{\text {re }}$ semaine $(35-42 \mathrm{j}$ d'âge $)$

(Ist week (35-42 days old))

$2^{\mathrm{e}}$ semaine (42-49 j d'âge).

(2nd week (42-49 days old)

$3^{\mathrm{e}}$ et $4^{\mathrm{e}}$ semaines (49-63 j d'âge)

(3rd and 4 th weeks $(49-63$ days old)

Mortalité (p. cent)

(Mortality (p. cent))

\begin{tabular}{|c|c|c}
0 & 20 & 40 \\
\hline & & \\
\hline $8 \mathrm{I}, \mathrm{I}$ & 80,3 & 84,3 \\
76,0 & 80,0 & 83,0 \\
72,3 & 76,1 & $7^{8,3}$ \\
& & \\
\hline 5 & 5 & 25 \\
\hline
\end{tabular}

\subsection{Chez le porc en croissance-finition}

La plupart des études consacrées à l'utilisation de la mélasse par le porc concernent l'animal entre 20 et IOO kg (HENkE, I933; IWANAGA et OTAGAKI, I959; Ferrando et Theodossiades, I960; Blanco, RaUn et Vargas, I964; Preston et al., I968; Brooks et IWANAGa, I967; Combs et Wal,ace, I973; HaNsen, Sunesen et BREsson, I974; Babatunde, Fetuga et OvenugA, I975). Les principaux résultats expérimentaux sont rassemblés dans la figure 3. Il apparaît clairement que jusqu'au taux de $30 \mathrm{p}$. cent de la ration du Porc de 20 à Ioo kg, les performances de croissance demeurent pratiquement constantes grâce à une augmentation des quantités d'aliment ingéré. Au delà de ce taux, on constate une baisse des performances, aussi bien de la vitesse de croissance que de l'efficacité alimentaire (fig. 3), liées à la faible teneur en énergie digestible de la mélasse. En effet, comme le montre le tableau 6 , il semble possible d'améliorer les performances de croissance des Porcs à l'engrais en augmentant la concentration énergétique de la ration mélassée (BROOKS, I972). 

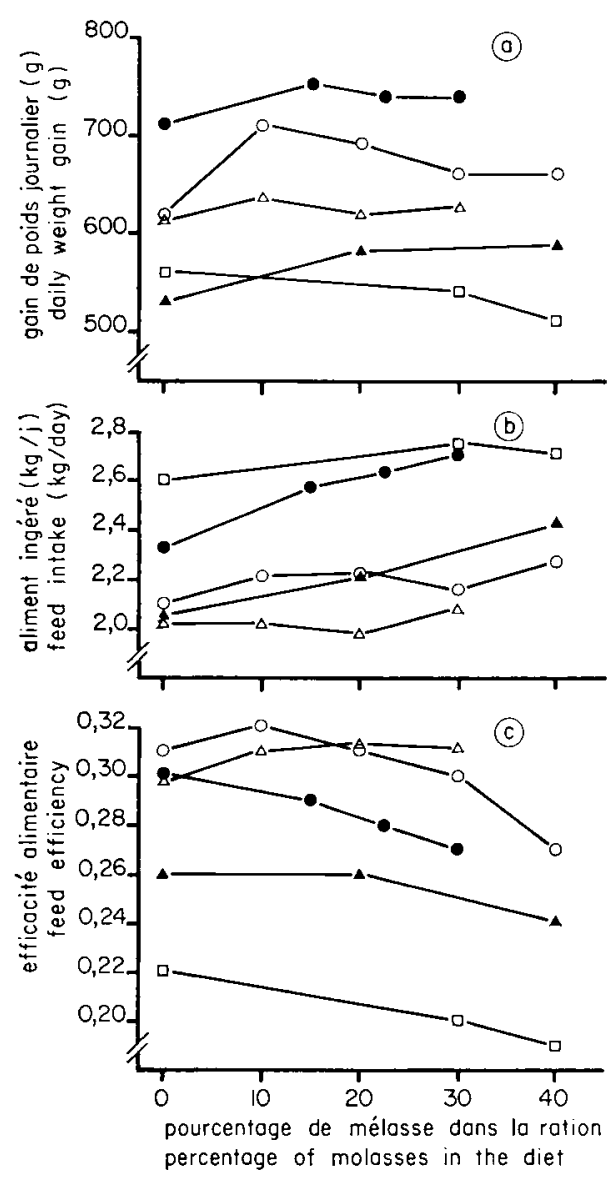

FIG. 3. - Effet du taux de mélasse dans la ration sur les performances de croissance (a), la consommation d'aliments (b) et l'efficacité alimentaire (c) selon différents auteurs: OBANDO et al., 1969 (๑); Hansen, SUnesen et Bresson, I974 ( 4 ); Babatendf, Fe'tuga et Oyenuga, 1975 (0); BACSTAD, 1973 (4); LE DIVIDICH et al., I974 (ם).

Effect of dietary level of molasses on growth rate (a), daily teed intake (b) and feed efficiency (weight gain, $k g$ /feed intake, $k g$ ) (c), according to OHANDO et al., I969 (•); HANSEN, SUNESEN

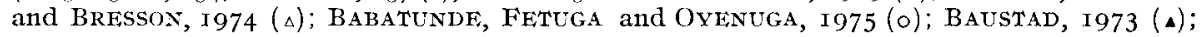
LE, DIVIDICH et al., 1974 ().

Cependant, en raison de sa consistance visqueuse, l'utilisation de taux élevés de mélasse pose le problème du choix des autres constituants de la ration et notamment d'un "support" adéquat qui puisse améliorer la texture de l'aliment final. Selon Brooks et Iwanaga (Ig67) et LE Dividich et al. (I974), la bagasse, résidu cellulosique de la canne, peut améliorer la texture de l'aliment mélassé. Mais ce "support " de nature essentiellement cellulosique ( $92 \mathrm{p}$. cent de constituants membranaires), accentue la dilution énergétique de la ration, entraîne une baisse importante (tabl. 7) de la digestibilité de l'énergie et de l'azote et une diminution consécutive des performances de croissance. Au contraire, l'association son de blémélasse est intéressante sur le plan économique car elle permet l'utilisation de ces deux constituants à des taux élevés. Toutefois, au delà de $30 \mathrm{p}$. cent de mélasse 


\section{TABLEAU 6}

liffet de l'augmentation de la concentration énergétique d'une vation riche en mélasse sur la vitesse de croissance et l'efficacité alimentaire (BRoOKs, I972)

Effect of increasing the energy concentration of a high-molasses diet on growth rate and feed efficiency (BRooks, I972)

\begin{tabular}{|c|c|c|c|c|}
\hline $\begin{array}{c}\text { Régime } \\
\text { (Diet) }\end{array}$ & & & & $\begin{array}{l}\text { Régime témoin } \\
\text { (Control diet) }\end{array}$ \\
\hline 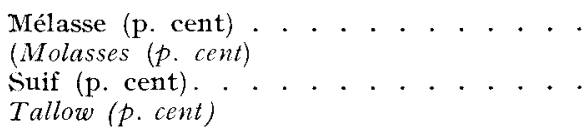 & $\begin{array}{r}50 \\
5\end{array}$ & $\begin{array}{l}40 \\
10\end{array}$ & $\begin{array}{l}30 \\
20\end{array}$ & $\begin{array}{c}\text { Mais-soja } \\
\text { (Maize-soya bean) }\end{array}$ \\
\hline 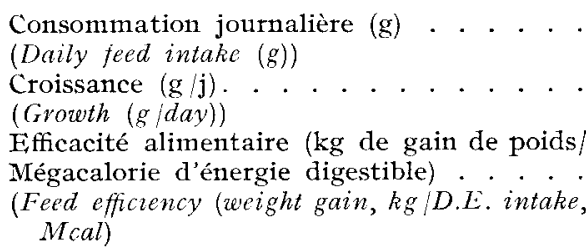 & $\begin{array}{r}2.185 \\
590\end{array}$ & $\begin{array}{l}\text { I } 922 \\
64^{\circ}\end{array}$ & $\begin{array}{l}\text { I } 72 \\
637\end{array}$ & $\begin{array}{r}2100 \\
700 \\
0,095\end{array}$ \\
\hline
\end{tabular}

\section{TABLEAU 7}

Eflet de la bagasse sur l'humidité des fèces et la digestibilité de l'énergie et de l'azote de la ration (LE DIVIDICH et al., I974, données non publiées)

Elfect of bagasse on faeces moisture and digestibility of dietary energy and protein (LE Drvioich et al., I974, unpublished data)

Composition des régimes

(Composition of the diets)
Mélasse ( $p$. cent)

(Molasses ( $p$. cent $)$ )

Saccharose (p. cent)

(Sucrose p. cent))

Bagasse (p. cent) .

(Bagasse $(p$. cent $))$

Coefficient de digestibilité apparente :

(Apparent digestibility coefficient:)

Énergie (p. cent)

(Energy (p. cent))

Protéines (p. cent)

(Protein (p.cent))

\begin{tabular}{|c|c|c}
\hline I & 2 & 3 \\
\hline 32 & 29 & 26 \\
32 & 29 & 26 \\
0 & 6 & $\mathbf{I} 2$ \\
\hline & & \\
\hline $91,3^{\mathbf{a}}$ & $86,3^{\mathrm{a}}$ & $79,4^{\mathrm{c}}$ \\
$87,2^{\mathrm{a}}$ & $83,9^{\mathrm{b}}$ & $79,3^{\mathrm{c}}$ \\
\hline
\end{tabular}


dans la ration, on assiste également à une diminution des performances de croissance, alors que l'efficacité de l'énergie digestible demeure constante (fig. 4).

En définitive, le taux de 30 p. cent de mélasse dans la ration du porc de 20 à Ioo $\mathrm{kg}$ constitue une limite maximum compatible avec une croissance optimum des animaux. A des taux supérieurs, en effet, le porc n'est plus capable de compenser le déficit énergétique de la ration par une augmentation suffisante des quantités de matière sèche et d'énergie digestible ingérées.

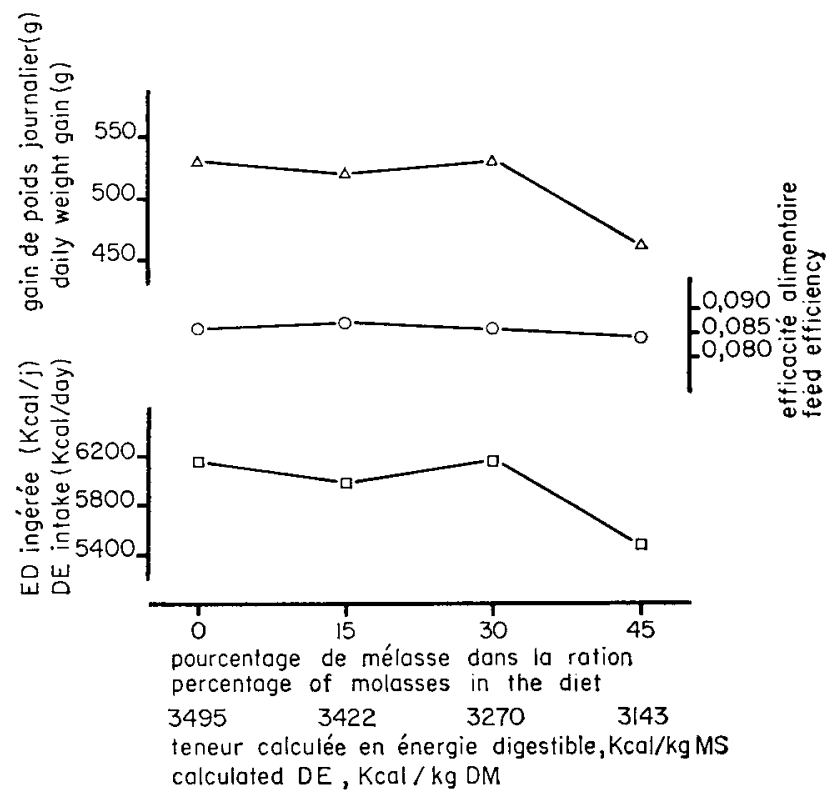

FIG. 4. - Influence du taux de mélasse, dans une ration contenant 35 p. cent de son de blé, sur les performances de croissance du porc de 30 à $95 \mathrm{~kg}$ de poids vif ( $\Delta)$, la quantité d'énergie digestible ingérée (a) et l'efficacité de l'énergie digestible (O) (LE DIVIDICH et CANOPE, données non publiées).

Effect of level of molasses, in a diet contient $35 p$. cent fine wheat bran on the growth performances on the pig from 30 to $95 \mathrm{~kg}$ liveweight ( $\Delta)$, the D.E. intake ( $\square$ ) and the efficiency of D.E. (O) ( $\mathbf{L}_{\mathbf{E}}$ DIVIDICH and CANOPE, unpublished data).

\subsection{Chez la truie en reproduction}

Les travaux expérimentaux ayant trait à l'utilisation de mélasse dans les aliments de la truie en reproduction sont peu nombreux. Selon Brooks et IwaNAGA (I967), l'introduction de $38 \mathrm{p}$. cent de mélasse dans la ration de gestation n'a aucune conséquence néfaste sur les performances de mise bas de la Truie, en ce qui concerne la fécondité et la fertilité (tabl. 8). Par contre, utilisée en lactation, la mélasse entraîne une perte de poids importante. Ceci est sans doute la conséquence d'une ingestion réduite d'énergie, eu égard à l'importance des besoins énergétiques de lactation. I'analyse du tableau 8 montre, en outre, que l'introduction de mélasse dans les aliments de la mère n'est pas sans conséquence sur la croissance des porcelets. En effet, pour un poids égal à la naissance, les porcelets allaités par les truies recevant le régime mélassé sont plus légers à $2 \mathrm{r}$ jours $(-0,6 \mathrm{~kg})$ et encore plus à 42 jours $(-2,3 \mathrm{~kg})$ que ceux du lot témoin. On peut donc affirmer que 


\section{TABLEAU 8}

Effet de la mélasse dans l'alimentation sur les performances de la truie en reproduction gestation et lactation (Brooks et IWANAGA, 1967)

Effect of including molasses into the diet on performances of sows during gestation and lactation

(BROOKS and IWANAGA, I967)

Gain de poids total pendant la gestation $(\mathrm{kg})$

(Total weight gain during gestation $(\mathrm{kg})$ )

Perte de poids en lactation $(\mathrm{kg})$.

(Weight loss during lactation $(\mathrm{kg})$ )

Mélasse dans la ration

(p. cent)

Critères

(Parameters)

Nombre de porcelets à la naissance.

(Number of pigs farrowed)

Nombre de porcelets vivants à 2 I jours . . . . . . . . .

(Live piglets at $2 I$ days)

Poids des porcelets à la naissance (kg)

(Birth weight/pig (kg))

Poids des porcelets à $2 \mathrm{I}$ jours $(\mathrm{kg})$

(Weight of $2 I$ days old piglets $(k g)$ )

Poids des porcelets à 42 jours $(\mathrm{kg})$

(Molasses in the diet)

(p. cent)

(Weight of 42 days old piglets $(\mathrm{kg})$ )

\begin{tabular}{l|l}
\hline & 37
\end{tabular}

l'ingestion de mélasse chez la truie allaitante diminue la production laitière dans de fortes proportions, entraînant des baisses de performances sur toute la portée. Il découle de ces observations que la mélasse peut être utilisée jusqu'à environ 40 p. cent par la truie en gestation, mais que, durant la phase de lactation, son taux d'incorporation dans 1'aliment doit être fortement limité.

Dans l'état actuel de nos connaissances, on peut conclure que la faible valeur énergétique de la mélasse constitue l'un des principaux facteurs limitant les performances $d u$ porc soumis à un régime qui en contient une forte proportion. Il semblerait possible, cependant, de les améliorer en élevant la concentration énergétique du régime à l'aide d'une addition de lipides, mais cette dernière recommandation s'avère souvent antiéconomique en raison de ses répercussions sur le coût de l'aliment final.

\section{4. - Effet de la mélasse sur le développement des viscères et la composition corporelle du Porc}

L'influence de la mélasse sur les caractéristiques de la carcasse a été peu décrite et les données qui s'y rapportent sont très limitées.

Toutefois, d'après les données bibliographiques, l'ingestion de mélasse n'exerce 
TABLEAU 9

Influence du taux de mélasse dans la ration sur le vendement en carcasse et l'épaisseur du lard dorsal

Effect of level of dietary molasses on the dressing percentage and the backlat thickness

\begin{tabular}{|c|c|c|c|c|c|}
\hline & & \multicolumn{4}{|c|}{ AUTEURS (Authors) } \\
\hline $\begin{array}{c}\text { Critères } \\
\text { (Parameters) }\end{array}$ & $\begin{array}{c}\text { Taux de mélasse } \\
(\mathrm{p} . \text { cent) } \\
\text { (Level of molasses) } \\
(\mathrm{p} \text {. cent) }\end{array}$ & $\begin{array}{l}\text { BROOKS } \\
(1972) \\
80(1)\end{array}$ & $\begin{array}{l}\text { BAUSTAD } \\
(1973) \\
\text { I } 00\end{array}$ & $\begin{array}{c}\text { Lr: Drvidich } \\
\text { et al. } \\
(\mathrm{r} 974) \\
95\end{array}$ & $\begin{array}{c}\text { BABATUNDE } \\
\text { et al. } \\
(1975) \\
65\end{array}$ \\
\hline $\begin{array}{l}\text { Rendement } \\
\text { (p. cent) } \\
(\text { Dressing }) \\
(p . \text { cent })\end{array}$ & 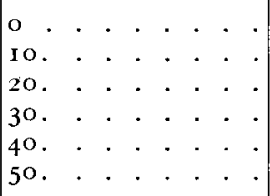 & $\begin{array}{l}75,0 \\
- \\
- \\
72,5 \\
71,3 \\
68,8\end{array}$ & $\begin{array}{l}75,6 \\
- \\
73,9 \\
\square \\
72,0 \\
-\end{array}$ & $\begin{array}{l}7 \mathrm{I}, 8 \\
- \\
- \\
73,4 \\
73,7 \\
-\end{array}$ & $\begin{array}{l}73,9 \\
73,1 \\
72,2 \\
72,5 \\
71,8 \\
-\end{array}$ \\
\hline $\begin{array}{l}\text { Ppaisseur du lard } \\
\text { dorsal (mm) } \\
\text { Backfat thichnes } \\
\text { (mm) }\end{array}$ & 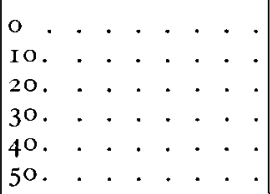 & $\begin{array}{l}37,0 \\
- \\
34,0 \\
29,0 \\
30,0\end{array}$ & $\begin{array}{l}\frac{26,3}{28,2} \\
-2,2 \\
-2\end{array}$ & $\begin{array}{l}30,1 \\
- \\
- \\
31,9 \\
30,9 \\
-\end{array}$ & $\begin{array}{l}29,0 \\
28,4 \\
26,4 \\
24,7 \\
24,6 \\
-\end{array}$ \\
\hline
\end{tabular}

(') Poids d'abattage (kg). (Slaughtering weight (kg).)

aucun effet particulier sur la qualité des carcasses et de la viande (MACLEOD et al., I968; QUIJANDRIA et BLENGERI, I974). Ces résultats ne permettent en aucun cas d'étayer la vieille pratique recommandant la distribution au Porc d'un repas mélassé juste avant l'abattage, afin d'augmenter les réserves glycogéniques du muscle et du foie et améliorer les conditions de maturation de la viande.

Sur le plan pratique, selon Preston et al. (I968), Brooks (I972), BAUSTAD (I973), LE Dividich et al. (I974), LE Dividich et Canope (I975) et BabaTunde et al. (I975), l'accroissement du taux de mélasse dans la ration s'accompagne le plus souvent d'une diminution du rendement en carcasse, consécutif à la réduction de la masse adipeuse à poids constant et à une augmentation significative du poids des viscères (tabl. 9). Du point de vue anatomique, on retiendra que les fortes proportions de mélasse entraînent une augmentation du poids du foie, du cour et des reins (BABATUNDE, FETUGA et OyENUGA, I975). Mais c'est surtout l'augmentation du poids du tractus digestif, notamment de l'intestin grêle vide, qui doit être retenue : l'ingestion de mélasse entraîne une adaptation de la fonction digestive chez le Porc. Une augmentation similaire du poids de l'intestin grêle vide a été mise en évidence chez le Rat soumis à un régime à base de mélasse (LE DIvIDICH $e t$ al., I977). 
2.5. - Effet de la mélasse sur l'état sanitaire des animaux

\subsection{La diarrhée}

En dehors des difficultés technologiques d'incorporation homogène dans les aliments, l'un des principaux facteurs limitant le taux d'introduction de la mélasse dans les aliments du Porc concerne la diarrhée qu'elle provoque. Ce phénomène est constaté chez la plupart des espèces animales domestiques et s'accompagne d'une baisse des performances et de la digestibilité des éléments de la ration (Brooks et IWANAGA, I967; Combs et WALlace, I973; LE Dividich et al., I974).

L'effet laxatif de la mélasse est le plus souvent attribué à sa teneur élevée en cendres et plus précisément en potassium (ROSENBERG et PALAFOX, I956, dans le cas du Poulet; FERrando et Theodossiades, I960, VElasquez, Ly et Preston, I969, dans le cas du Porc). Cependant, l'influence des cendres et du potassium est davantage "suspectée " que démontrée. Ainsi, la diminution de l'humidité des fèces constatée par VELAsquez, LY et PREston (I969) à la suite de la réduction de la teneur en cendres de l'aliment mélassé (tabl. Io), s'explique tout aussi bien par la diminution du taux de mélasse de la ration. De même, la surcharge en élément potassium (sous forme de carbonate ou de sulfate) d'un aliment à base de céréales ne modifie en aucun cas l'hydratation des fèces (MANER et al., I969; OBANdo et al., I969). La même observation a été effectuée chez le Poulet par Cuervo, Bushman et Dantos (I972) qui montrent, en outre, que la déminérali-

\section{TABLEAU IO}

Influence de la teneur en cendres d'un régime à base de mélasse sur l'humidité des fèces et les performances de croissance du Porc de 20 à $100 \mathrm{~kg}$

(VELASQUEZ, LY et PRESTON, rg69)

Influence of ash content of a molasses based diet on faeces moisture and growth performances of pigs from 20 to $100 \mathrm{~kg}$

(VELASQUEZ, Iry and PRESTON, I969)

\begin{tabular}{|c|c|c|c|}
\hline Régime (Diet) & I & 2 & 3 \\
\hline 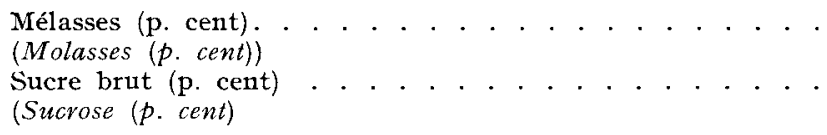 & $\begin{array}{l}55,0 \\
20,0\end{array}$ & $\begin{array}{l}39,5 \\
3^{6,0}\end{array}$ & $\begin{array}{r}23,5 \\
52,0\end{array}$ \\
\hline 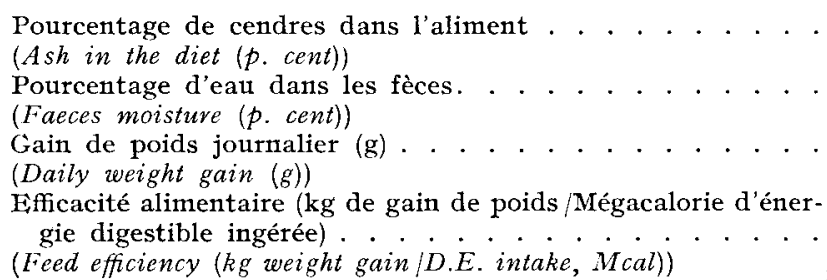 & $\begin{array}{r}9,5 \\
74,8^{a} \\
490\end{array}$ & $\begin{array}{r}8,4 \\
66,0^{b} \\
54^{\circ}\end{array}$ & $\begin{array}{c}7,2 \\
59,3^{\mathrm{c}} \\
560\end{array}$ \\
\hline
\end{tabular}


sation de la mélasse n'a aucune influence sur l'élimination d'eau par voie fécale. Par contre, le potassium alimentaire, qui est, principalement excrété par voie urinaire, peut provoquer une augmentation pondérale du rein et entraîner certaines lésions rénales à la suite d'une alimentation riche en mélasse (BrooKs, I972; Babatunde, Fetuga et Oyenuga, I975).

D'autres auteurs attribuent la diarrhée à une teneur insuffisante en cellulose de la ration. Ainsi, selon Brooks et IwanaGa (I967), LE Dividich et al. (I974), l'addition de bagasse au régime mélassé réduit sensiblement l'hydratation des fèces. Mais la déficience en cellulose de la mélasse ne semble pas suffisante pour expliquer la diarrhée. En effet, selon HENRY et ÉTIENNE, (I969), la teneur en eau des fèces aurait plutôt tendance à augmenter quand on ajoute de la cellulose à la ration du Porc. De plus, cet effet bénéfique de la bagasse sur l'humidité des excreta s'accompagne d'une diminution significative de la digestibilité de l'énergie et de l'azote ce qui va à l'encontre de son introduction dans les rations à base de mélasse.

En réalité, les causes de l'effet laxatif de la mélasse sont encore mal connues. Les glucides non digérés et/ou non absorbés, essentiellement saccharose, fructose et vraisemblablement les déhydroglucides et le mannitol pourraient bien en être l'origine. Leur accumulation dans la région iléo-cæcale et le gros intestin, tout en créant un milieu hypertonique (MEIHOFF et KERN, I968; Chongo, I976; Ly, I977) favoriserait le développement des fermentations microbiennes ayant pour conséquence une importante production d'acides organiques. Ces derniers, selon WEIJERS et VAN de KAMER (I965) peuvent, en irritant la muqueuse, entraîner une accélération du transit digestif. Mais cette dernière peut également être liée à 1'augmentation de 1'ingestion spontanée d'eau observée avec des régimes riches en mélasse (MARRERO et LY, I977).

Ainsi, l'incorporation de mélasse en proportions importantes dans le régime peut entraîner, chez l'animal, un certain nombre de troubles dont le plus fréquemment rapporté est la diarrhée. Les facteurs impliqués sont encore inconnus, bien que certaines hypothèses puissent être raisonnablement formulées. En fin, il semble qu'une adaptation préalable des animaux à l'ingestion de mélasse permette d'en limiter l'action laxative.

\section{Conclusion}

La mélasse finale de canne à sucre, qui présente une forte teneur en constituants glucidiques, est un aliment essentiellement énergétique. Son taux optimum d'incorporation dans les aliments du Porc varie de $20 \mathrm{p}$. cent (porcelets à partir de $7 \mathrm{~kg}$ ) à $30 \mathrm{p}$. cent (porc en croissance-finition et truie en gestation).

Sur le plan nutritionnel, la valeur alimentaire de la mélasse est limitée par :

- sa faible teneur en énergie digestible qui, sur la base de la matière sèche, ne représente que 80 à $90 \mathrm{p}$. cent de celle des céréales;

- la diminution de la rétention azotée, liée à un accroissement de l'excrétion fécale d'origine endogène, qu'elle entraîne chez le Porc.

Sur le plan digestif, l'ingestion de mélasse s'accompagne d'une augmentation des activités totale et spécifique de l'invertase intestinale chez le Rat. Il semble que l'on puisse également retenir une telle hypothèse chez le Porc, ce qui met en relief l'importance d'une adaptation progressive de l'animal et surtout du jeune 
porcelet à ce type d'aliment. La diarrhée qui apparaît chez le porc recevant une alimentation riche en mélasse a sans doute plusieurs origines, mais elle ne semble pas constituer un inconvénient majeur à son emploi chez l'animal à partir de $20 \mathrm{~kg}$ de poids vif.

Accepté pour publication en décembre 1977.

\author{
Summary \\ Utilization of sugar cane molasses in pig teeding: \\ Interpretation of recent data.
}

The objective of this review is to give a survey of data obtained the last 20 years on the chemical composition of cane final molasses and the utilization of this feed in pig diets.

Molasses, whose water content reaches $I_{5}$ to $25 \mathrm{p}$. cent, contains a large carbohydrate fraction : its nitrogen free extract represents about $65 \mathrm{p}$. cent of the fresh product, mainly composed of water or alcohol soluble carbohydrates $(58.7 \mathrm{p}$. cent) such as sucrose (34.6 p. cent), glucose $(8.5 \mathrm{p}$. cent) and fructose $(9.9 \mathrm{p}$. cent); about $7 \mathrm{p}$. cent of the carbohydrate fraction has not been identified yet. On the contrary, molasses is poor in nitrogen $(0.56 \mathrm{p}$. cent), while its content of inorganic matter is high. Thus, molasses represents a high energy nutrient because of its carbohydrate constituents, although its gross energy level is relatively low $(2850 \mathrm{Kcal} / \mathrm{kg}$ crude product, $3800 \mathrm{Kcal} / \mathrm{kg}$ dry matter).

Addition of high amounts of cane molasses to the diet (Io to $40 \mathrm{p}$. cent in weight) has consequential effects on the overall performance of monogastric animals and the function of their digestive tract. In piglets as well as in pigs from 20 to $100 \mathrm{~kg}$ live weight a reduction of growth performance and feed efficiency was noticed. This effect can be reduced in growingfinishing pigs by increasing the energy concentration of the molasses diet with a high energy nutrient. Furthermore, the intake of high molasses levels is followed by a decrease in the carcass dressing percentage, particularly due to an increase in the weight of the digestive tract and to a decrease in the carcass fatness.

Decrease in the performance of the young pigs as well as in that of the older ones results from the low digestible energy level of molasses $(2.400 \mathrm{Kcal} \mathrm{D} . \mathrm{E} . / \mathrm{kg})$ and the depressing effect on nitrogen retention, mainly due to a larger excretion of faecal metabolic nitrogen. Moreover, addition of increasing levels of molasses to the diet of pigs (especially that of piglets) brings about a sometimes fatal diarrhoeic state. These digestive disorders cannot entirely be explained by the high ash content (and mainly the potassium content) of the molasses or by the deficiency in ballast. They are probably the result of an incomplete digestion and /or absorption of molasses carbohydrates creating a hypertonic medium favourable to fermentation. Increase in the specific activity of the intestinal invertase noticed in rats receiving molasses diets seems to show that - like in the piglet-a previous adaptation of the animals to this feed improves its utilization.

For obtention of maximum performance, the optimum level of cane molasses in the diet may vary from zo p. cent in piglets to $30 \mathrm{p}$. cent in growing-finishing pigs and pregnant sows.

\title{
Références bibliographiques
}

Aguilera J., Bo7a J., Fonolila J. et Escriva J., I97I. Experiencias de utilizacion de dietas con melazas en cerdos en crecimiento-cebo. Rev. Nutr. Animal, 9, I39-144.

Aumaitre; A. et Salmon-LEGagnedr E, ig6I. Influence de l'alimentation complémentaire sur 1a croissance du porcelet avant le sevrage. Ann. Zootech., 10, I27-140.

Aumaitre A., Rerat A., Vaissade P. et Vaugelade P., I975. Mesure quantitative en continu de l'absorption intestinale des glucides : effet de l'ingestion de saccharose sur la concentration en glucose et en fructose dans le sang porte et périphérique chez le porc. Ann. Biol. anim. Bioch. Biophys., 15, 547-558. 
BABATUNDE G. M., FETUGa B. L. et OYHNUGA V. A., I975. Fffects of feeding graded levels of cane molasses on the performance and carcass characteristics and organ weights of Yorkshire pigs in a tropical environment. $J$. Anim. Sci., 40, 632-639.

BAUSTAD B. M., T973. A preliminary note on the use of molasses in the feeding of growing pigs. E. Afr. Agric. Forest. J., 34, 203.

BINKLEY W. W. et WOLFrom M. I., I953. Composition of cane juice and cane final molasses. Adv. Carbohydrate Chem., 8, 29I-3I2.

BLAIR D. G. R., YAKIMFTS W. et TUBA J., I963. Rat intestinal sucrase. II. The effects of rat age and sex and of diet on sucrase activity. Can. J. Bioch. Physio., 41, 917-929 (abstr).

Blanco V., Racn N. S. et Vargas E., I 964 . Molasses as a major energy source for swine. $J$. Anim. Sci., 23, 868 (abstr).

BRoOks C. C., I967. Effect of sex, fat, fiber, molasses and thyroprotein on digestibility of nutrients and performance of growing swine. J. Anim. Sci., 26, 495-499.

Brooks C. C., I972. Molasses, sugar (sucrose), corn, tallow, soybean oil and mixed fats as sources of energy for growing swine. J. Anim. Sci, 34, 217-z24.

Brooks C. C. et Iwanaga I. I., I967. Use of cane molasses in swine diets. J. Anim. Sci., 26, $74 \mathrm{I}-745$.

Chongo Garcia B. B. M., I976. Étude de la digestion intestinale de la mélasse de canne à sucre chez le veau préruminant. Thèse Université de Clermont II, France, $90 \mathrm{p}$.

Christon R. et LE DIVIDICH J., I977. Effect of feeding cane molasses on nitrogen digestibility and retention in the rat. Nutr. Rep. Inter., 16, 549-555.

Combs G. E. et Waldace M. D., I970. Cane molasses for growing swine. Anim. Sci. Mimeo. Series Io. Gainesville (Florida).

COMBS G. E. et WALrACE H. D., I973. Utilization of high dietary levels of cane molasses by young and by growing-finishing swine. Anim. Sci. Res. Report., 49, 73-I Gainesville (Florida).

CoRr C. F., I925. The fate of sugar in the animal body. I. The rate of absorption of hexoses and pentoses from the intestinal tract. J. Biol. Chem., 66, 69I-7I 5 .

Cufrvo C., Bushman D. H. et Dantos E., I972. The effect of deionization and drying of cane molasses on their laxative action in chicken. Poultry Sci., 51, 82 I-824.

DEREN J. J., BROITMAN S. A. et ZAMCHECK N., I967. Effect of diet upon intestinal disaccharidases and disaccharide absorption. J. Clin. Invest., 46, I86-195.

DEvendra C. et Gohr B. I., I970. The chemical composition of caribbean feeding-stuffs. Trop. Agric. Trin. (Trinidad), 47, 335-342.

Diniz M. I., BARbosa A. S., Veloso J. A. F. et ANdrade, I973. Éfeitos da substituiçào parcial du milho por melaço desidratado na alimentaçào de suinos ein crescimento-terminaçào. Arq. Esc. Vet. Belo Horizonte (Brasil), 25, 67-84.

Food and Agriculture Organization of the United Nations (F.A.O.) Rome, I976. Production Yearbook., 30, I6r.

Ferrando R. et Theodosstades G., i960. La mélasse dans l'alimentation du bétail. Vigot Frères, éd., I I $8 \mathrm{p}$.

Fincham J. E., I966. Note on the nutritional value of Rhodesian molasses Rodhesia $A$ gric. J., 63, Io6. Cité par Nutv. Abstv. Rev., I967, (3), 4266.

Grand R. J., JAKsina M. D. et Jaksina S., I973. Additional studies on the regulation of carbohydrate-dependent enzymes in the jejunum: changes in amino-acid pools, protein synthesis and the effects of actinomycin-D. Gastroenterology, 64, 429-437.

Hansen V., Sunesen N. et Bresson S., I974. Melasse og rasukker som foder til slagterisvin. Bevetn. Fø rsogslab., 415, 5-24.

Hashizume T., Yamagami T. et Sasaki Y., 1967. Constituents of cane molasses. Agr. Biol. Chem., 31, 324-329.

HeNkE L. A., I933. Cane molasses as a supplement to fattening rations for swine. Hawaii A gric. Exp. Station., bull. $\mathrm{n}^{0} 69$, I I p.

HENRY Y., r968. Utilisation comparée des céréales comme seuls aliments du porc perıdant la période de finition. Ann. Zootech., 17, I83-197.

HENRY Y. et ETIENNE M., I 969. Effets nutritionnels de l'incorporation de cellulose purifiée dans le régime du porc en croissance-finition. I. Influence sur l'utilisation digestive des nutriments. Ann. Zootech., 18, 337-357.

IWANAGA I. I. et OTAGAKI K. K., I959. High molasses rations for growing-fattening swine. Proc. West. Sec. Am. Soc. Anim. Prod., 10, 27. 
Jones D. P., SOSA F. R. et SKromak E., I972. Effects of glucose, sucrose and lactose on intestinal disaccharidases in the Rat. J. Lab. Clin. Med., 79, I9-30.

(L.A.T.F.C.), Latin American Tables of Feed Composition 1974, Florida, 509 p.

Le Dividich J., Seve B., Canope I. et KempF H., I974. Essai d'utilisation de fortes proportions de mélasse de canne à sucre dans les rations du porcelet sevré à 5 semaines et du porc en croissance-finition. Journées Rech. Porcine en France, 6, I99-207. I.N.R.A.-I.T.P., éd. Paris.

LE Dividich J. et CANope I., I975. Utilisation de la mélasse finale de canne à sucre dans 1'alimentation du porc : influence de la teneur en énergie des régimes sur les performances du porcelet; utilisation métabolique de l'azote chez le porc à $35 \mathrm{~kg}$. Journées Rech. Porcine en France, 7, I 45-I 50. I.N.R.A.-I.T.P. éd., Paris.

Le Dividici J., Christox R., Peiniad J. et Aumaitre A., 1978. Proximate analysis of final cane molasses and effect of feeding $30 \%$ molasses on intestinal sucrase and maltase activities in the rat. Anim. Feed. Sci. Techn. 3, I5-22.

Ifewis C. J., Cetron D. V., Combs G. E. Jr., Ashion G. C. et Culbertson C. C., i955. Sugar in pig starters. J. Anim. Sci, 14, IIO4-1 II5.

Ly J., I97I. Contribution al estudio de la digestion de mieles en cerdos en crecimiento. Thesis I.C.A. Universidad de la Habana, Cuba, ro4 p.

LY J., r977. Studies on the digestive distribution along GIT of pig fed high test molasses or maize. 2. Intestinal stage. Cuban J. Agric. Sci, 11, 47-62.

Macleod N. A., Preston T. R., Lassota L. A., Willis M. B. et Velasquez M., ig68. Molasses and sugar as energy sources for pigs. Rev. Cubana Cienc. Agric., 2, 205-zIO.

Maner J., Gali,o J., Corzo M. et Buitrago J., ig69. Effect of minerals in cane molasses on performance and faecal moistrure of pigs. J. Anim. Sci., 29, г39 (Abstr.).

Manners M. J., Stevens J. A., I972. Changes from birth to maturity in the pattern of distribution of lactase and sucrase in the mucosa of the small intestine of pigs. Br.J. Nutr., 28, I I 3 I 28 .

MARRERO L. et Ly J., I977. An approach to water metabolism in pigs fed sugar cane final molasses. I. Main routes of water excretion and digestibility of the proximal nutrients. Cuban J. Agric. Sci, 11, 39-46.

Mегнон W. E. et KeikN F. Jr., I968. Bile salt malabsorption in regional ileitis, ileal resection and mannitol-induced diarrhea. J. Clin. Invest., 47, 261-267.

Monetri P. G., 1967. Utilizzazione del melasso nel razionamento dei suini. Riv. Zootech. Agric. Vet., 4, I $32-\mathrm{I} 47$.

Morrison F. B., I954. Feeds and Feeding. $2 \mathrm{I}^{\mathfrak{E}}$ éd. The Morrison Publ. Company Ithaca, New York, 607-608.

Notzold R. A., Becker D. E., Terrili, S. W. et Jensen A. H., I955. J. Anim. Sci., 14, io68IO72.

N.R.C. (National Research Council), I969. United States - Canadian Tables of feed composition, second revision. National academy of Sciences. Publ. I684. Washington, D.C.

Obando H., Corzo M., Moncada A. et Maner J. H., i969. Estudios del valor nutritivo de la melaza para cerdos. Rev. I.C.A., 4, 3-29.

Priston T. R., i972. Molasses as an energy source for cattle. World Rev. Nutr. Diet., 17, 250-3II.

Preston T. R., Machfod N. A., Lassota L., Wilitis P. B. et Velasquez Mi, ig68. Sugat cane products as energy sources for pigs. Natuve, 219, 727-728.

QUJANDRIA B. et BI.ENGERI W., I974. Uso de altos niveles de melaza on raciones deshidratadas para cerdos en crecimiento y acabado. Univ. Nac. Agr. Peru (Lima), Informe Tec. (3), I-5o.

REDDY B. S., PIEASANTS J. R. et WoSTMANN B. S., ig68. Effect of dietary carbohydrates on intestinal disaccharidases in germfree and conventional Rats. J. Nutr., 95, 4I3-4I9.

Rosentberg M. M. et Palafox A. L., I956. Effect of certain cations in cane final molasses on fecal moisture in chicks. Poultry Sci, 35, 68z-686.

RoSENSWeig N. S. et Herman R. H., ig68. Control of jejunal sucrase and maltase activity by dietary sucrose or fructose in man. A model for the study of enzyme regulation in man. J. Clin. Invest., 47, 2253-2262.

Satimox-LEgagnitur E., Fevrier R., i956. Les préférences alimentaires du porcelet. II. Le sucre dans les aliments pour porcelets. Ann. Zootech., 5, 87-93.

Sco'T M. I., I953. Use of molasses in the feeding of farm animals. Sugar Research Foundation Technological Report, Series $n^{\circ}$ 9, I 5 p. 
STEVENS J. A. et KIDDER D. E., I972. The distribution of trehalase, sucrase, $\alpha$-amylase, glucoamylase and lactase ( $\beta$-galactosidase) along the small intestine of five pigs. $B r . J$. Nutr., 28, I29-137.

StEvens R., I957. The phenolic constituents of sugar cane. Ann. Rev. Plant-Physiol., 15, ig9.

Tuovinen C. G. R. et BeNDER A. F., I975. Some metabolic effects of prolonged feeding of starch, sucrose, fructose and carbohydrate-free diet in the Rat. Nutr. Metabol., 19, I6I-I 72.

Velasquez M., Ly J., Preston T. R., 1969. Digestible and metabolizable energy values for pigs of diets based on high-test molasses or final molasses and sugar. J. A nim. Sci,, 29, 578-580.

WEIJERS H. A. et VAN DE KAMER J. H., I965. Alteration of intestinal bacterial flora as a cause of diarrhoea. Nutr. Abstr. Rev., 35, $59 \mathrm{I}-604$.

Yokota M. et FAGERSON I. S., T97T. The major volatile components of cane molasses. $J$. Fd. Sci., 36, I09I-I094. 